\title{
Molecular and cellular effects of contamination in aquatic ecosystems
}

\author{
Miriam Hampel $^{1,2} \cdot$ Julian Blasco $^{3} \cdot$ Helmut Segner $^{4}$
}

Received: 30 September 2015 / Accepted: 6 October 2015 / Published online: 28 October 2015

(C) Springer-Verlag Berlin Heidelberg 2015

This special issue of Environmental Science \& Pollution Research on 'Molecular and cellular effects of contamination in aquatic ecosystems' contains a selection of 16 papers. Starting point for this issue was the FP7 Marie Curie IRSES action GENERA: Use of genomic and proteomic tools for the development of contaminant specific biomarkers for the environmental risk assessment of aquatic ecosystems (FP7PEOPLE-2009-IRSES-Proposal no. 247559). The International Research Staff Exchange Scheme (IRSES) is an EU-funded Marie Curie Action that aims to strengthen research partnerships between organizations from inside and outside Europe through staff exchange and networking activities. Additional contributions are made from researchers outside the GENERA consortium, equally motivated by the awareness of the increasing importance of molecular and cellular approaches in ecotoxicology.

Aquatic ecosystems are sinks for many chemicals and their degradation products with diverse modes of toxic actions. Chemicals reaching aquatic ecosystems include radioactive elements (strontium, cesium, radon), metals (cadmium,

Responsible editor: Philippe Garrigues

Miriam Hampel

miriam.hampel@icman.csic.es

1 Department for Physical Chemistry, Faculty of Marine and Environmental Sciences, University of Cadiz, 11510 Puerto Real, Spain

2 Andalusian Centre for Marine Science and Technology (CACYTMAR), 11510 Puerto Real, Spain

3 Andalusian Institute for Marine Sciences (CSIC), 11510 Puerto Real, Spain

4 Centre for Fish and Wildlife Health, University of Bern, Bern, Switzerland mercury, lead), industrial solvents and volatile organic compounds (tri- and tetrachloroethylene, chlorofluorocarbons, benzene, xylenes, formaldehyde), agrochemicals (fertilizers, pesticides), household products (detergents, cleaners, paints), fuel combustion (nitrogen and sulphur oxides, polycyclic aromatic hydrocarbons, carbon monoxide, carbon dioxide), nanoparticles, personal care products, microplastics, antibiotics as well as a huge variety of prescription and nonprescription drugs and pharmaceuticals of human and veterinary medicine. Despite advances in wastewater treatment technologies, rising global emissions of these chemicals, in particular also the increasing use of specifically acting chemicals such as pharmaceuticals, convert chemical contamination into an important threat to aquatic ecosystems (e.g. Schwarzenbach et al. 2006, Hughes et al. 2013, Larsson 2014, Malaj et al. 2014). Thus, maintaining the quality of aquatic ecosystems represents one of the most formidable challenges facing global society in the twenty-first century.

Why are molecular and cellular approaches of value in assessing the hazards which are posed by contaminants upon aquatic ecosystems? While in the last century, often huge levels of contaminants lead to massive mortalities and other alarming responses; the challenge nowadays is more the longterm, low-dose effects of chemicals and their mixtures. Therefore, traditionally, hazard assessment is based on toxicity studies that qualify and quantify the injurious effects of chemical agents on the basis of primarily apical effects such as death, growth or alterations of reproductive success. Chronic low-dose effects, however, may not cause overt toxicities but may cause adverse ecological outcomes through rather subtle changes in the health and physiological traits (e.g. behaviour) of the aquatic organisms. Thus, the former view that only apical responses are responsible for changes in population growth and survival has shifted towards the understanding that also subtle toxicant effects can have 
ecological relevance (Relyea and Hoverman, 2006). This may be particularly relevant for chemicals with specific modes of action (e.g. Segner 2011, Shore et al. 2014). An example is provided by the experimental lake study of Kidd et al. (2007, 2012): dosing a Canadian lake over 3 years with about $5 \mathrm{ng} \mathrm{L}^{-1}$ of the pharmaceutical ethinylestradiol did not cause any mortalities among the exposed fish species but caused specific molecular, cellular and physiological changes which eventually inhibited successful recruitment thereby leading to extinction of fish species such as fathead minnow. Interestingly, not all fish species were affected, what appears to be on one hand related to differences of physiological properties among the exposed species, but on the other hand, it relates to indirect effects of the chemical exposure on the food web of the lake. To be able to detect and understand such complex effects and the involved causative processes, investigations at the cellular and molecular levels are as essential as studies of ecological processes.

Studying molecular and cellular processes is also of value for prioritization of chemicals for hazard testing as well as for interspecies extrapolation. With over 30,000 substances produced above $1 \mathrm{t}$ per year on the EU market and eventually discharged into the environment, the traditional descriptive, compound-by-compound approaches are coming to their limits, from both an economic as well as a time-consuming point of view. Molecular and cellular approaches are of value to overcome these limitations as they explore the principal toxicity pathways. Thus, they can alert on specific hazardous potentials of chemicals, and they can assist in grouping chemicals according to their modes of action (Diamond et al. 2011; Segner 2011). With the adverse outcome pathway (AOP) concept suggested by Ankley et al. (2010)), a framework is available which links data collected from lower levels of biological organization through the use of, e.g. highthroughput screening, toxicogenomic assays, in vitro cellular assays or histopathological assessments to higher levels of biological organization, although it must not be overlooked that the effect propagation is neither deterministic nor always linear (Ankley et al. 2010); Segner 2011). Chemicals with specific modes of action may also target specific ecological receptors or specific life stages of a given species and thereby cause toxic effects that are not predicted from standard ecotoxicological risk assessment. Here, molecular and cellular approaches can inform which ecological receptor groups, which life stages or which functions and traits are likely to be at risk by a given group of chemicals (Hutchinson et al. 2006; Yadetie et al. 2012; Segner et al. 2013; Brown et al., 2014).

Finally, molecular and cellular tools are also useful in field monitoring for diagnosing actual pollution impacts on wildlife and for unraveling exposure-effect relationships. Molecular and cellular tools are instrumental for the detection of sublethal, chronic effects and their relation to ecological alterations (Relyea and Hoverman 2006). As formulated by Boxall et al.
(2003)) for the case of veterinary medicines, 'despite concentration and effects data indicate that acute environmental impacts are unlikely..., some researchers have raised concerns over ...the potential longer -term and subtle effects of these medicines'. Molecular and cellular tools are particularly relevant in the (early) detection of such subtle toxicant effects. The example of biomarkers witnesses the utility of molecular and cellular tools in environmental assessment. Overall, the new mechanism-based assessment approaches support evidence-based risk assessment where uncertainty is explicit and to improve our ability to diagnose and predict adverse effects of chemical pollution.

The increasing application of molecular and cellular approaches in ecotoxicology is also related to the huge technical progress of the relevant methodologies over the last decades. The development of cDNA microarrays and oligo arrays for global transcriptome analysis, or advances in mass spectrometry for proteomic and metabolomic studies have allowed scanning the array of products/molecules generated under a certain (environmental) condition. However, in many cases in ecotoxicology, their implementation is still hampered by the lack of sequencing and annotation of the genomes of nontarget organisms. Moreover and despite all enthusiasm on the new possibilities, it is not the use of a particular technique per se but it still needs a sound study design and interpretation. As put by Miracle et al. (2003): 'If a well thought-out approach is neglected during experimental design and data interpretation (of molecular technologies), then we are simply left with standard toxicology in Technicolor'. Likewise, we must understand the molecular and cellular tools and give emphasis to their technical quality (Harris et al. 2014; Wolf et al. 2015); in particular, as ecotoxicologist are not necessarily trained as molecular biologists, bioinformaticians or histopathologists, but still are using and applying these techniques.

Despite the important scientific efforts made and the information gathered on molecular and cellular effects of environmental toxicants in a broad range of species, the development of mechanism-oriented molecular and cellular approaches in environmental risk assessment remains a challenging task and requires the joint effort of the scientific community. Here, this special issue gathers a critical mass of molecular and cellular effect data to advance in the understanding of the toxic mode of action of selected model contaminants including existing (the synthetic organofluorine PFOSA, the surfactant linear alkylbenzene (LAB), the endocrine-active compound estradiol and metals such as cadmium and mercury) and emerging (the nonsteroidal anti-inflammatory drug or analgesic ibuprofen and different metallic nanoparticles) as well as radiation (gamma), apart from three field or in situ exposure studies. The contributions cover a variety of field and laboratory approaches aiming to identify contaminant-specific responses in order to rationalize the environmental risk assessment process. With this issue, we want to provide a broad forum of 
discussion and knowledge-sharing to the reader interested in the use of molecular and cellular tools in ecotoxicology.

One topic covered in this issue is the evaluation of transcriptomic responses by quantitative reverse transcription PCR, often in combination with other enzymatic and/or cellular biomarkers. The use of transcriptomic approaches is still limited in ecotoxicology, probably due to the combination of economical and technical aspects, the latter referring to the lack of genomic resources in poorly or not annotated nontarget organisms. Studies that involved the evaluation of effects on proteome level are even less frequent. An example of the use of proteomics is provided in this issue by the study of Flores-Nunes et al. 2015a, b. Hook et al. (2015) exemplifies how to utilize contaminant-specific gene expression patterns for the purpose of a toxicity identification evaluation (TIE)like approach. The evaluation of stressor-specific gene response patterns was also addressed in the study of Karray et al. $(2015 \mathrm{a}, \mathrm{b}, \mathrm{c})$ in the marine bivalve Cerastoderma glaucum exposed to cadmium or industrial effluents containing high concentrations of metals. These genes showed to provide a rapid and synchronic mechanism to prevent cellular damage by handling and exporting metal ions through the upregulation of ATP-binding cassette xenobiotic transporter (ABCB1) and metallothionein (MT), antioxidant enzymes, heat shock protein 70 and cytochrome c oxidase 1 . These authors also carried out an evaluation of the reproductive cycle, condition index and glycogen reserves of the cockle, Cerastoderma glaucum from the Gulf of Gabès (Tunisia), providing information for the sustainable management of stocks (Karray et al. 2015c).

A further study on metal toxicity was carried out with yellow perch, Perca flavescens, from mercury-contaminated lakes in Canada (Müller et al. 2015). The study showed a clear relation between a specific cellular reaction in the liver-the formation of macrophage aggregates - and the level of mercury burdens in the fish.

One of two in vitro studies included in this issue used cadmium as model contaminant to study effects on the viability and phagocytic activity of primary cultures of haemocytes from the gastropod mollusc Haliotis tuberculata (LadharChaabouni et al. 2015) In the second in vitro study, primary salmon hepathocyte cultures were exposed to the synthetic organofluorine PFOSA either in the presence or absence of chemically induced hypoxia and transcriptomic responses were measured. The findings from this investigation highlight the utility of in vitro systems for analysing the combination effects of stressors (Olufsen and Arukwe 2014). Another combination study examining the impact of chemical mixtures on Nile tilapia in vivo is presented by Ferreira-Rodrigues et al. (2015) These authors exposed tilapia to combinations of $17 \beta$ estradiol (E2) and benzo(a)pyrene (BaP) and found that the endocrine-active compound altered the $\mathrm{BaP}$-induced activation of the biotransformation pathways.
Two studies employed the Pacific oyster, Crassostrea gigas, as model organism to evaluate the transcriptome (Serrano et al. 2015) and proteome (Flores-Nunes et al. 2015a, b responses towards exposure to ibuprofen and urban sewage, respectively. Environmentally relevant concentrations of the nonsteroidal anti-inflammatory drug ibuprofen produced increased transcription of cytochrome P450 genes, glutathione S-transferase isoforms, as well as the cyclooxygenase-like and the fatty acid-binding protein-like features, and alterations on antioxidant and auxiliary enzymes, which could, in the long term, cause damages to exposed individuals of $C$. gigas. On the other hand, urban sewage exposure resulted in expression changes of proteins related to the cytoskeleton, ubiquitination pathway conjugation, $G$ protein coupled receptor and signal transduction and cell cycle/division with different protein expression signatures at different sites and suggest that these changes might lead to DNA damage, apoptosis and interference with the immune system. Ibuprofen was also employed to evaluate its chronic effects at low and high concentrations in the euryhaline fish, Menidia beryllina (Jeffries et al. 2015). This species exhibited clear concentration-related differences of gene expression responses. Low exposure concentrations silenced many genes involved in skeletal development, aerobic respiration and immune function, whereas highest exposure concentrations induced the expression of regulatory genes in the arachidonic acid metabolism pathway and several immune genes involved in an inflammatory response, what agrees with the known mode of action of anti-inflammatory drugs.

Nanoparticles, as a contaminant group of emerging concern, were in the focus of studies with marine bivalves - the Manila clam, Ruditapes philippinarum (Volland et al. 2015) and the mussel, Mytilus galloprovincialis (Bebianno et al. 2015) - and in a study with the bacterial model organism Escherichia coli using a genome-wide toxicogenomic approach (Su et al. 2015). The Manila clam was used to examine uptake, elimination as well as oxidative stress response under exposure to gold nanoparticles. The particles were readily taken up into the digestive gland $>$ gills of the clam producing limited oxidative stress and initiating inflammatory responses. $M$. galloprovincialis exposure to $10 \mu \mathrm{g} \mathrm{L}^{-1}$ silver nanoparticles over 2 weeks did not elicit significant changes in gene transcription profiles of selected genes (superoxide dismutase (SOD), catalase (CAT), glutathione transferase (GST), caspase 3/7-1 (CAS), cathepsin L (CATH), heat-shock protein 70 (HSP 70), cytochrome P450 4YA (CYP 4YA), the elongation factor (EF1), actin and $\alpha$-tubulin). Exposure of the bacterium Escherichia coli to nano zinc oxide particles (nano- $\mathrm{ZnO}$ ) resulted in pronounced changes of the transcriptomic profile, with 387 genes showing significant alterations in translation, gene expression, RNA modification and structural constituent of ribosome. 
The importance of radioactive material as potential marine contaminant was recently brought to attention again by the Fukushima accident. Release of nuclides into the ocean is causing health risks to marine organisms and humans. Won et al. (2015)) review the known effects of gamma-irradiation on aquatic organisms and analyse their results attempting to link molecular and cellular effects of exposure to physiological adverse effects employing marine copepods, with estimations for the whole ecosystem effects.

The contributions to this special issue highlight both the progress and the still existing bottlenecks for routine employment of molecular and cellular techniques in ecotoxicology. While quantitative real time polymerase chain reaction (qRTPCR) is meanwhile a routine technique in many laboratories, other methodologies such as 2D DIGE or iTRAQ in proteomics and microarray or even RNAseq in transcriptomics are not widely used yet. The latter techniques, in contrast to measuring preselected genes or proteins, like qRT-PCR, offer an open, unbiased analysis of a broad spectrum of potential targets, what is invaluable when considering the complexity of stressor combinations in ecosystems which are likely to induce unexpected, diverse responses. Thus, the use and development of molecular and cellular techniques in ecotoxicology has not yet reached an end but has to be taken further in order to be able to deal with the complexity of ecotoxicological effects.

This issue was only possible with the generous contribution of the authors and the journal's editors who handled the submissions. Miriam Hampel wishes to thank the European Commission for the financial support under the GENERA Project (Reference: (FP7-PEOPLE-2009-IRSES_-Proposal no. 247559).

\section{References}

Ankley GT, Bennett RS, Erickson RJ, Hoff DJ, Hornung MW, Johnson RD, Mount DR, Nichols JW, Russom CL, Schmieder PK, Serrrano JA, Tietge JE, Villeneuve DL (2010) Adverse outcome pathways: a conceptual framework to support ecotoxicology research and risk assessment. Environ Toxicol Chem 29(3):730-741

Bebianno MJ, Gonzalez-Rey M, Gomes T, Mattos JJ, Flores-Nunes F, Bainy ACD (2015) Is gene transcription in mussel gills altered after exposure to Ag nanoparticles? Environ Sci. Pollut. Res, SI GENERA. doi:10.1007/s11356-015-5186-Z

Boxall ABA, Kolpin DW, Halling Sorensen B, Tolls J (2003) Are veterinary medicines causing environmental risks? Environ Sci Technol 37:286-294

Brown AR, Gunnarsson L, Kristianson E, Tyler CR (2014) Assessing variation in the potential susceptibility of fish to pharmaceutcials, considering evolutionary differences in their physiology and ecology. Philos Trans Roy Soc B369:20130576. doi:10.1098/rstb.2013. 0576

Diamond JM, Latimer HA, Munkittrick KR, Thorntn KW, Bartell SM, Kidd KA (2011) Prioritizing contaminants of emerging concern for ecological screening assessments. Environ Toxicol Chem 30:2385-2394
Ferreira-Rodrigues AC, de Oliveira MT, Toyoko Shiraishi Frighetto R, Alves de Almeida E (2015) E2 potentializes benzo(a)pyrene-induced hepatic cytochrome P450 enzyme activities in Nile tilapia at high concentrations. Environ Sci Pollut Res, SI GENERA. doi:10. 1007/s11356-014-3670-5

Flores-Nunes F, Gomes T, Company R, Moraes RRM, Sasaki ST, Taniguchi S, Bicego MC, Melo CMR, Bainy ACD, Bebianno MJ (2015a) Changes in protein expression of pacific oyster Crassostrea gigas exposed in situ to urban sewage. Environ Sci Pollut Res. doi: 10.1007/s11356-014-3821-8, SI GENERA

Flores-Nunes F, Mattos JJ, Zacchi FL, Serrano MAS, Piazza CE, Sasaki ST, Taniguchi S, Bicego MC, Melo CMR, Bainy ACD (2015b) Effect of linear alkylbenzene mixtures and sanitary sewage in biochemical and molecular responses in pacific oyster Crassostrea gigas. Environ Sci Pollut Res. doi:10.1007/s11356-015-4486-7, SI GENERA

Harris CA, Scott AP, Johnson AC, Panter GH, Sheahan D, Roberts M, Sumpter JP (2014) Principles of sound ecotoxicology. Envrion Sci Technol 48:3100-3111

Hook SE, Osborn HL, Spadaro DA, Simpson SL (2015) Challenges for using quantitative PCR test batteries as a TIE-type approach to identify metal exposure in benthic invertebrates. Environ Sci Pollut Res. doi:10.1007/s11356-014-3234-8, SI GENERA

Hughes SR, Kay P, Brown LE (2013) Global synthesis and critical evaluation of pharmaceutical data sets collected form river systems. Environ Sci Technol 47:661-677

Hutchinson TH, Ankley GT, Segner H, Tyler CR (2006) Screening and testing for endocrine disruption in fish-biomarkers as signposts, not traffic lights, in risk assessment. Environ Health Perspect 114: $106-114$

Jeffries KM, Brander SM, Britton MT, Fangue NA, Connon RE (2015) Chronic exposures to low and high concentrations of ibuprofen elicit different gene response patterns in a euryhaline fish. Environ Sci Pollut Res. doi:10.1007/s11356-015-4227-y, SI GENERA

Karray S, Marchand J, Moreau B, Tastard E, Thiriet-Rupert S, Geffard A, Delahaut L, Denis F, Hamza-Chaffai A, Chénais B (2015a) Transcriptional response of stress-regulated genes to cadmium exposure in the cockle Cerastoderma glaucum from the gulf of Gabès area (Tunisia). Environ Sci Pollut Res. doi:10.1007/s11356-0143971-8, SI GENERA

Karray S, Tastard E, Moreau B, Delahaut L, Geffard A, Guillon E, Denis F, Hamza-Chaffai A, Chénais B, Marchand J (2015b) Transcriptional response of stress-regulated genes to industrial effluent exposure in the cockle Cerastoderma glaucum. Environ Sci Pollut Res. doi:10.1007/s11356-015-4108-4, SI GENERA

Karray S, Smaoui-Damak W, Rebai T, Hamza-Chaffai A (2015c) The reproductive cycle, condition index, and glycogen reserves of the cockles Cerastoderma glaucum from the Gulf of Gabès (Tunisia). Environ Sci Pollut Res. doi:10.1007/s11356-015-4337-6, SI GENERA

Kidd KA, Blanchfield PJ, Mills KM, Palace VP, Evans RE, Lazorchak JM, Flick KR (2007) Collapse of a fish population after exposure to a synthetic estrogen. Proc Natl Acad Sci USA 104:8897-8901

Kidd KA, Paterson MJ, Rennie MD, Podemski CL, Findlay DL, Blanchfield PJ, Liber K (2012) Direct and indirect responses of a freshwater food web to a potent synthetic oestrogen. Philos Trans Roy Soc B 369:20130578

Ladhar-Chaabouni R, Machreki-Ajmi M, Serpentini A, Lebel JM, Hamza-Chaffai A (2015) Does a short-term exposure to cadmium chloride affects haemocyte parameters of the marine gastropod Haliotis tuberculata? Environ Sci Pollut Res. doi:10.1007/s11356014-3387-5, SI GENERA

Larsson DGJ (2014) Pollution from drug manufacturing: review and perspectives. Philos Trans R Soc B 369:20130571. doi:10.1098/ rstb.2013.0571 
Malaj E, von der Ohe PC, Grote M, Kühne R, Mondy CP, UsseglioPolatera P, Brack W, Schäfer RB (2014) Organic chemicals jeopardize the health of freshwater ecosystems on the continental scale. Proc Natl Acad Sci U S A 111:9549-9554

Miracle AL, Toth GP, Lattier DL (2003) The path from molecular indicators of exposure to describing dynamic biological systems in an aquatic organism: microarrays and fathead minnow. Ecotoxicology 12:457-462

Müller AK, Brinkmann M, Baumann L, Stoffel MH, Segner H, Kidd KA, Hollert H (2015) Morphological alterations in the liver of yellow perch (Perca flavescens) from a biological mercury hotspot. Environ Sci Pollut Res. doi:10.1007/s11356-015-4177-4, SI GENERA

Olufsen M, Arukwe A (2014) Endocrine, biotransformation, and oxidative stress responses in salmon hepatocytes exposed to chemically induced hypoxia and perfluorooctane sulfonamide (PFOSA), given singly or in combination. Environ Sci Pollut Res. doi:10.1007/ s11356-014-3847-y, SI GENERA

Relyea R, Hoverman J (2006) Assessing the ecology in ecotoxicology: a review and synthesis in freshwater systems. Ecol Lett 9:1157-1171

Schwarzenbach RP, Escher BI, Fenner K, Hofstetter TB, Johnson CA, von Gunten U, Wehrli B (2006) The challenge of micropollutants in aquatic systems. Science 313:1072-1077

Segner H (2011) Moving beyond a descriptive aquatic toxicology: the value of biological process and trait information. Aquat Toxicol 105:50-55

Segner H, Casanova-Nakayama A, Kase R, Tyler CR (2013) Impact of environmnetal estrogens on fish considering the diversity of estrogen signaling. Gen Comp Endocrinol 191:190-201

Serrano MAS, Gonzalez-Rey M, Mattos JJ, Flores-Nunes F, Mello ACP, Zacchi FL, Piazza CE, Siebert MN, Piazza RS, Alvarez-Muñoz D, Rodriguez-Mozaz S, Barceló D, Bebianno MJ, Gomes CHAM, Melo CMR, Bainy ACD (2015) Differential gene transcription, biochemical responses, and cytotoxicity assessment in pacific oyster crassostrea gigas exposed to ibuprofen. Environ Sci Pollut Res. doi:10.1007/s11356-014-4023-0, SI GENERA

Shore RF, Taggart MA, Smits J, Mateo R, Richards NL, Fryday S (2014) Detection and drivers of exposure and effects of pharmaceuticals in higher vertebrates. Philos Trans Roy Soc B 369:20130570

Su G, Zhang X, Giesy JP, Musarrat J, Saquib Q, Alkhedhairy AA, Yu H (2015) Molecular mechanism comparison between nano zinc oxide $(\mathrm{ZnO})$ particles and free zinc ion using a genome-wide toxicogenomics approach. Environ Sci Pollut Res. doi:10.1007/ s11356-015-4507-6, SI GENERA

Volland M, Hampel M, Martos-Sitcha JA, Trombini C, MartínezRodríguez G, Blasco J (2015) Citrate gold nanoparticle exposure in the marine bivalve Ruditapes philippinarum: uptake, elimination and oxidative stress response. Environ Sci Pollut Res. doi:10.1007/ s11356-015-4718-x, SI GENERA

Wolf JC, Baumgartner WA, Blazer VS, Camus AS, Engelhardt JA, Fournie JW, Frasca S Jr, Groman DB, Kent ML, Khoo LH, Law JM, Lombardini ED, Ruehl-Fehlert C, Segner HE, Smith SA, Spitsbergen JM, Weber K, Wolfe MJ (2015) Non-lesions, misdiagnoses, missed diagnoses, and other interpretive challenges in fish histopathology studies: a guide for investigators, authors, reviewers, and readers. Toxicol Pathol 43:297-325

Won EJ, Dahms HU, Kumar KS, Shin KH, Lee JS (2015) An integrated view of gamma radiation effects on marine fauna: from molecules to ecosystems. Environ Sci Pollut Res. doi:10.1007/s11356-014-37974, SI GENERA

Yadetie F, Butcher S, Forde HE, Campstejn C, Bouquet JM, Karlsen OA, Denoued F, Metpally R, Thompson EM, Manak JR, Goksoyr A, Chourrot D (2012) Conservation and divergence of chemical defense system in the tunicate Oikopleura dioica revelaed by genome wide responses to two xenobiotics. BMC Genomics 13:55-63

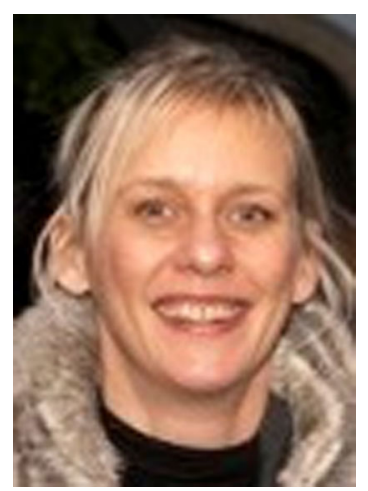

Miriam Hampel obtained her $\mathrm{PhD}$ in Chemistry in 2003 at the University of Cadiz (Spain). After 3 years of post doctoral at the Research Institute for Fisheries and the Sea (IPIMAR) Lisbon (Portugal), she was awarded with a Marie Curie fellowship at the Institute of Aquaculture in Stirling (Scotland). In 2009, she joined the Institute for Marine Sciences of Andalusia (ICMAN) funded by a Post Doctoral contract of the Spanish National Council for Scientific Research (CSIC) and a European Marie Curie Reintegration grant, where she focused on the genomic effects and mechanisms of actions of environmentally relevant exposure concentrations in several non-target organisms. From 2011 to 2013 she coordinated the Marie Curie International Research Exchange Scheme Action: Use of genomic and proteomic tools for the development of contaminant-specific biomarkers for the environmental risk assessment of aquatic ecosystems (GENERA), a network for staff and expertise exchange including five European and five non-European countries. At present, she is a Senior Researcher (Funding scheme: Ramón y Cajal) at the Andalusian Centre for Marine Science and Technology (CACYTMAR) of the University of Cadiz (Spain). Her research interests are the evaluation of molecular and cellular effects of existing and emerging contaminants for mechanism-based environmental risk assessment, bioinformatics and integration of high-throughput data for data exploitation.

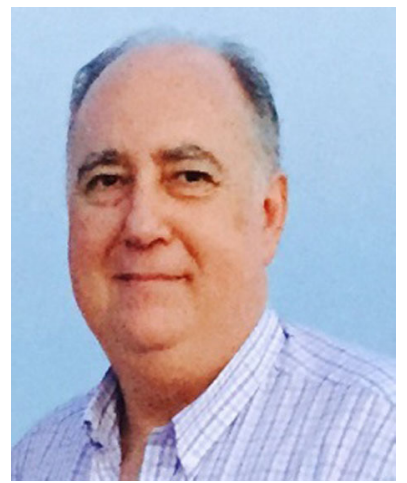

Julián Blasco is senior scientist in the Instituto de Ciencias Marinas de Andalucía (ICMAN) belonging to the Spanish $\mathrm{Na}$ tional Research Council (CSIC). He obtained his $\mathrm{Ph}$. D. in the University of Seville (1985). He was head of the Department of Oceanography (1998-2007) and Ecology and Coastal Management (2007-2001) of ICMAN, and currently, he is the Director of the Institute. He was Associate Professor of the University of Cádiz in the Physical-Chemistry Department (1994-1998). He is Associate Editor of Frontiers in Marine Science (Marine Pollution) and member of the editorial board of the journals Environment International, Environmental Toxicology and Chemistry and Marine Environmental Research and guest editor of the journal Science Total Environment, Scientia Marina and Ciencias Marinas. The scientific objectives, during his career have been focused on the behaviour and distribution of legacy and emergent pollutants and their ecotoxicological effects. He has developed and applied novel bioassays and tools to assess the environmental risks associated with pollutants. Over the last years, he has focused on the study of emergent pollutants (pharmaceuticals and nanoparticles), for improving the environmental risk assessment of these substances in aquatic ecosystems. The next steps of his research are focusing on the impact of contaminant mixtures (legacy and emergent), reflecting global changes scenarios. 


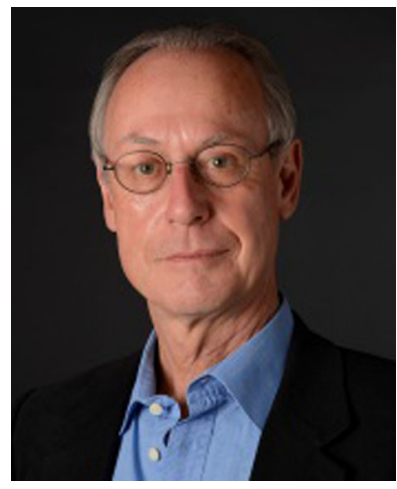

Helmut Segner obtained his $\mathrm{PhD}$ in Zoomorphology and ecology in 1985 at the University of Heidelberg. After 2 years in the R\&D Department of the ornamental fish food manufacturer, Tetra Company, he returned to academia taking up an assistant professor position in the Department of Zoophysiology at the University of Karlsruhe. In 1992, he moved to the newly founded Helmholtz Centre for Environmental Research Leipzig, where he led the Aquatic Toxicology Laboratory.
Since 2000, he is professor and head of the Centre for Fish and Wildlife Health at the University of Bern. His research focuses on (i) the molecular and physiological acclimation of fish towards environmental stressors (toxic chemicals, pathogens, temperature), with emphasis on the responses of the endocrine and immune systems, and (ii) the development of non-animal testing strategies for ecotoxicological hazard assessment. H. Segner has been involved in numerous national and international research projects and he coordinated two EU projects. He has published more the 200 papers in ISI journals and he serves on the editorial board of eight ISI journals. 